\title{
Сорбционное концентрирование фенолов из водных сред магнитными молекулярно импринтированными полимерами на основе $\mathrm{N}$-винилпирролидона
}

\author{
(C) 2021 Губин А.С., Кушнир А.А., Суханов П.Т. \\ Воронежский государственньй университет инженерных технологий, Воронеж \\ Поступила в редакцию 26.01.2021 г.
}

DOI: $10.17308 /$ sorpchrom.2021.21/3466

Фенолы одна из наиболее обширных групп приоритетных органических загрязнителей с мутагенными и канцерогенными свойствами. Они характеризуются очень низкими предельно допустимыми концентрациями, которые сложно определить многими современными физико-химическими методами без предварительного концентрирования. Решение этой задачи достигается современными подходами твердофазного концентрирования, в частности, применением молекулярно импринтированных полимерных сорбентов с магнитными свойствами. Изучена возможность получения магнитного сорбента на основе молекулярно импринтированного полимера (МИП), где в качестве функционального мономера применен N-винилпирролидон, сшивающий агент - этиленгликольдиметакрилат, а в качестве темплатов использованы фенолы.

Синтезированы девять МИП с отпечатками 2-хлорфенола, 4-хлорфенола, 2-нитрофенола, 4нитрофенола, бисфенола А, n-трет-бутилфенола, нонилфенола, трет-нонилфенола, 4-октилфенола и полимера без молекулярных отпечатков. Размер частиц полученных полимеров около 100 нм, намагниченность насыщения 51-53 emu/g. Наибольшие импринтинг-факторы $(I F)$ достигнуты для МИП с отпечатками 4-нитрофенола $(I F=3.8)$ и бисфенола А $(I F=7.1)$, наименьшие - с отпечатками хлорфенолов $(I F=1.1)$. Установлено, что наиболее эффективно фенолы сорбируются при рН 3. Наибольшие значения коэффициентов селективности достигаются при сорбции на МИП-4НФ и МИП-БФА. Степени извлечения фенолов МИП составили от 69 до 96\%, для 2-НФ не более 45\%, на неимпринтированном полимере эффективность извлечения для большинства фенолов существенно ниже.

Ключевые слова: сорбция, фенолы, хлорфенолы, нитрофенолы, молекулярно импринтированный полимер.

\section{Введение}

Фенолы - большая группа загрязнителей, поступающих в природные среды из антопогенных источников [1]. Помимо общетоксического действия они воздействуют на центральную нервную систему, повреждают печень, почки и иммунную систему человека [2]. Согласно нормативам РФ, содержание фенолов в водоемах рыбохозяйственного и культурно-бытового назначения в питьевой воде нормируются от 0.02 до $0.0001 \mathrm{мг} /$ дм $^{3}$ [3-5], что при проведении анализа вод- ных сред требует включения стадии предварительного концентрирования.

Твердофазная экстракция (ТЭ) широко применяется при определении фенолов из-за огромного ассортимента доступных сорбентов и минимального расхода растворителей по сравнению с жидкостной экстракцией $[6,7]$. Применение ТЭ ограничивается токсичностью растворителей, дорогостоящих картриджей и многостадийностью пробоподготовки (фильтрация пробы, необходимая для предотвращения засорения концентрирующего элемента, кондициониро- 


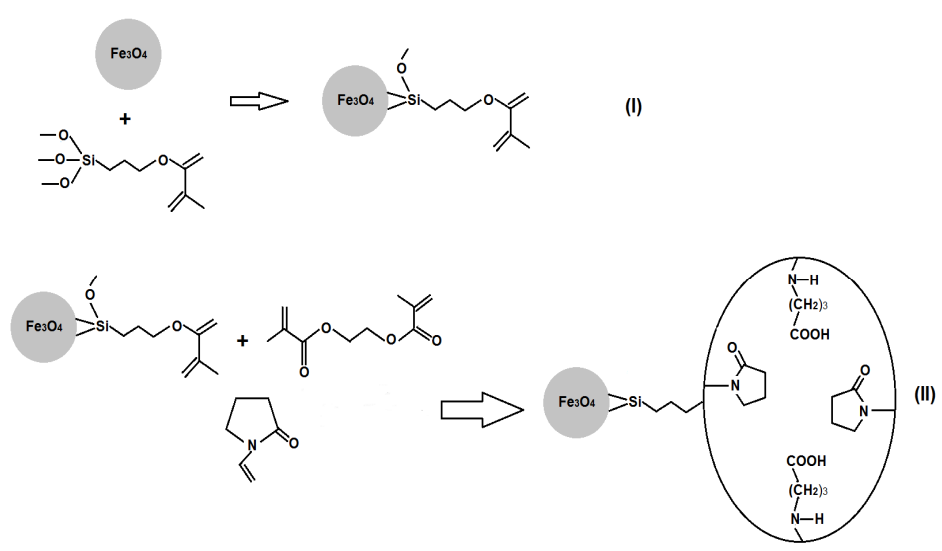

Рис. 1. Схема синтеза молекулярно импринтированного полимера (I - модификация поверхности $\mathrm{Fe}_{3} \mathrm{O}_{4} \mathrm{MOTC}$; II - синтез МИП, молекула-темплат не показана).

Fig. 1. Scheme for the synthesis of a molecularly imprinted polymer (I - modification of the surface of $\mathrm{Fe}_{3} \mathrm{O}_{4} \mathrm{MPS}$; II - MIP synthesis, template molecule not shown)

вание картриджа, загрузка образца и т.д.) [8]. Неселективность к определяемому аналиту может привести к совместному извлечению других нежелательных компонентов из анализируемой матрицы [9]. Для повышения селективности определения и извлечения фенолов предлагается применение молекулярно импринтированных полимеров (МИП). Они разработаны практически для всех групп фенолов [10-13] на основе функциональных мономеров (ФМ) - итаконовой кислоты, 4-винилпиридина (4-ВП), стирола и сшивающих агентов (CA) - мономеры с этиленгликольдиметакрилатом (ЭГДМА), триэтиленомдиметакрилатом гликоля или триакрилатпентакритритола, а также фенолов в качестве темплатов [14].

Современным подходом, обеспечивающим высокие степени извлечения и коэффициенты концентрирования, является применение магнитных сорбентов, поверхность которых покрыта различными модификаторами [15]. Применение таких сорбентов (например, $\mathrm{Fe}_{3} \mathrm{O}_{4} @$ МИП [16], $\mathrm{Fe}_{3} \mathrm{O}_{4} @ \mathrm{SiO}_{2}$, [17], $\mathrm{Fe} @ \mathrm{Fe}_{2} \mathrm{O}_{3} /$ оксид графена [18] и других) обеспечивает практически полное извлечение фенолов из водной матрицы, в том числе из мутных сред, и быстрое достижение сорбционного равновесия [19].

Цель работы - изучить возможность получения магнитного сорбента с МИП, где в качестве ФМ применен $\mathrm{N}$ винилпирролидон (НВП), а в качестве темплатов - фенолы: 2-хлорфенол (2ХФ), 4-хлорфенол (4-ХФ), 2-нитрофенол (2-НФ), 4-нитрофенол (4-НФ), бисфенолА (БФА), $n$-трет-бутилфенол (ПТБФ), нонилфенол (НЛФ), трет-нонилфенол (ТНЛФ), 4-октилфенол (4-ОФ) и его изомеры.

\section{Экспериментальная часть}

Приборы, реактивы и материалы. Для синтеза сорбентов применялись приборы, материалы и реактивы, аналогичные работе [20]. Идентификацию функциональных групп выполняли методом ИКспектрометрии (ИК Фурье-спектрометр ИнфраЛЮМ ФТ-08, приставка НАTR PIKE Technologies ${ }^{\mathrm{TM}}$ ). Удельную площадь поверхности сорбента $S_{\text {уд }}\left(\mathrm{M}^{2} / \Gamma\right)$ устанавливали методом БЭТ на анализаTope TRISTAR II 3020, размер частиц сорбента оценивали на сканирующем электронном микроскопе JSM-6510LV (Jeol, Япония). Просвечивающую электронную микроскопию проводили с помощью просвечивающего электронного микроскопа Libra 120 (Carl Zeiss, Германия). Магнитные кривые получали с применением вибрационного магнитометра Lake Shore 7410 (Lake Shore Cryotronics, США). Рентгенофазовый анализ проводили на дифрактометре XCalibur (Oxford diffraction, Великобритания). 


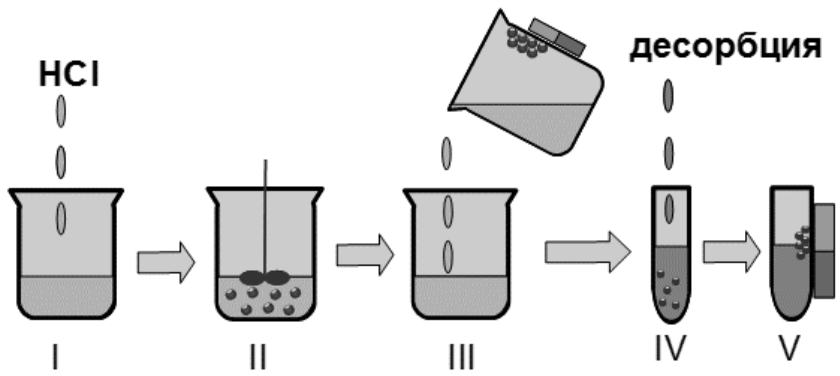

Рис. 2. Схема выполнения эксперимента по изучению сорбционных характеристик магнитных молекулярно импринтированных полимеров (I - подкисление до $\mathrm{pH} 3$;

II - добавление магнитного сорбента и перемешивание; III -извлечение магнитного сорбента; IV - десорбция растворителем или раствором щелочи; $\mathrm{V}$ - извлечение магнитного сорбента).

Fig. 2. Schematic diagram of an experiment to study the sorption characteristics of magnetic molecularly imprinted polymers (I - acidification to $\mathrm{pH} 3$; II - adding a magnetic sorbent and mixing; III - extraction of the magnetic sorbent; IV - desorption with a solvent or alkali solution; $\mathrm{V}$ - extraction of the magnetic sorbent).

Синтез молекулярно импринтированных полимеров. Стадия 1. Модификаиия поверхности магнетита метакрилоксипропилтриметоксисиланом. По методике [21] получали наночастицы $\mathrm{Fe}_{3} \mathrm{O}_{4}$ и модифицировали их метакрилоксипропилтриметоксисиланом (МОТС) (рис 1, схема I).

Стадия 2. Получение неимпринтированных (НИП) и молекулярно импринтированных полимеров. Первоначально получали НИП, проводя модификацию поверхности частиц $\mathrm{Fe}_{3} \mathrm{O}_{4} @ \mathrm{MOTC}$, полученных на стадии 1 , полимером методом суспензионной полимеризации [21] при соотношении ФМ (НВП) / СА (ЭГДМА) $-1: 15$. Далее, в отличие от работы [21], при указанном соотношении синтезировали 9 полимеров с молекулярными отпечатками соответствующего фенола 2-ХФ, 4-ХФ, 2-НФ, 4-НФ, БФА, ПТБФ, НЛФ, ТНЛФ и 4-ОФ (в предполимеризационную смесь вводили 2 ммоль соответствующего фенола), получая, соответственно, МИП-2ХФ, МИП-4ХФ, МИП-2НФ, МИП-4НФ, МИП-БФА, МИП-ПТБФ, МИП-НЛФ, МИП-ТНЛФ и МИП-4ОФ. Структура шаблона представлена на рис 1, схема II.

Изучение сорбции в статических условиях. 0.05 г сорбента помещали в сосуд, добавляли $10 \mathrm{~cm}^{3}$ растворов ис- следуемых фенолов с исходной концентрацией $\mathrm{c}_{0}=10$ мкг $/ \mathrm{cm}^{3}$, перемешивали сорбент с применением магнитной мешалки. Для отделения сорбента от раствора применяли неодимовый магнит, который прижимали к стенке сосуда. Раствор сливали, равновесные концентрации сорбатов в нем устанавливали спектрофотометрически $\left(\lambda_{\max }=405\right.$ нм) по реакции с диазотированной сульфаниловой кислотой. Общая схема сорбционного концентрирования представлена на рис. 2. По полученным экспериментальным данным рассчитывали коэффициенты распределения $(D)$, степени извлечения $(R)$, коэффициенты селективности $(k)$ и величину импринг-фактора $(I F)$ [22].

Влияние $\mathrm{pH} .0 .05$ г сорбента помещали в сосуд, добавляли $10 \mathrm{~cm}^{3}$ растворов исследуемых фенолов с концентрацией

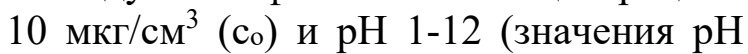
устанавливали добавлением соответственно растворов $\mathrm{HCl}$ или $\mathrm{NaOH}$ ), перемешивали раствор с сорбентом магнитной мешалкой.

Влияние массы сорбента. Сорбенты (0.01-0.07 г) помещали в сосуды, добавляли $10 \mathrm{~cm}^{3}$ растворов фенолов ( $\mathrm{c}_{0}=10$ мкг $\left./ \mathrm{cm}^{3}, \mathrm{pH} 3\right)$, перемешивали магнитной мешалкой. 
Таблица 1. Сорбция фенолов молекулярно импринтированными (МИП) и неимпринтированными (НИП) сорбентами ( $n=3, P=0.95 ; m=0.05$ г, $V=10 \mathrm{~cm}^{3}, t=30$ мин $\left.^{*}\right)$.

Table 1. Sorption of phenols by molecular imprinted (MIP) and non-imprinted (NIP) sorbents $(\mathrm{n}=3, \mathrm{P}=0.95 ; \mathrm{m}=0.05 \mathrm{~g}, \mathrm{~V}=10 \mathrm{ml}, \mathrm{t}=30 \mathrm{~min} *)$.

\begin{tabular}{|c|c|c|c|c|c|c|c|}
\hline \multirow[t]{2}{*}{ Вещество } & \multicolumn{2}{|c|}{$\begin{array}{c}\text { Удельная пло- } \\
\text { щадь поверх- } \\
\text { ности } S, \mathrm{~m}^{2} / \Gamma \\
\end{array}$} & \multicolumn{2}{|c|}{$\begin{array}{c}\text { Степень извлечения } \\
R, \%\end{array}$} & \multicolumn{2}{|c|}{$\begin{array}{c}\text { Коэффициенты распре- } \\
\text { деления } \\
D, \mathrm{~cm}^{3} / \Gamma \\
\end{array}$} & \multirow[t]{2}{*}{$I F$} \\
\hline & МИП & НИП & МИП & НИП & МИП & НИП & \\
\hline $2-X \Phi$ & 100 & 84 & $69 \pm 1$ & $68 \pm 2$ & $450 \pm 60$ & $425 \pm 55$ & 1.1 \\
\hline 4-XФ & 95 & 85 & $67 \pm 1$ & $65 \pm 2$ & $405 \pm 45$ & $370 \pm 45$ & 1.1 \\
\hline 2-HФ & 78 & 65 & $45 \pm 2$ & $25 \pm 3$ & $160 \pm 20$ & $68 \pm 7$ & 2.3 \\
\hline 4-HФ & 119 & 51 & $89 \pm 1$ & $68 \pm 2$ & $1620 \pm 15$ & $425 \pm 3$ & 3.8 \\
\hline БФА** & 125 & 77 & $96.0 \pm 0.4$ & $77 \pm 1$ & $4800 \pm 30$ & $670 \pm 7$ & 7.1 \\
\hline ПТБФ & 120 & 82 & $93 \pm 1$ & $84 \pm 1$ & $2650 \pm 24$ & $1050 \pm 11$ & 2.5 \\
\hline НЛФ & 109 & 74 & $92 \pm 1$ & $84 \pm 1$ & $2300 \pm 22$ & $1050 \pm 10$ & 2.2 \\
\hline ТНЛФ & 117 & 77 & $92 \pm 1$ & $84 \pm 1$ & $2300 \pm 23$ & $1050 \pm 11$ & 2.2 \\
\hline 4-ОФ & 94 & 82 & $91 \pm 1$ & $82 \pm 1$ & $2020 \pm 19$ & $910 \pm 10$ & 2.2 \\
\hline
\end{tabular}

* масса сорбента обоснована в работе [20], ** - при степени извлечения более $95 \%$ показатели $R$ определяли с точностью до десятых.

Построение кинетических кривых сорбции. Строили зависимости степени извлечения $(R, \%)$ от времени. Готовили растворы фенолов $\left(\mathrm{c}_{0}=10\right.$ мкг $\left./ \mathrm{cm}^{3}\right)$, добавляли 0.1 г сорбента, проводили сорбцию в соответствии с методикой, приведенной выше, отбирали пробы через 5, $10,20,30,40$ и 50 мин.

Десорбция фенолов. Десорбцию фенолов после извлечения сорбента из раствора магнитом и его высушивания проводили раствором $\mathrm{NaOH}$ (pH 10), ацетонитрилом или ацетоном. Для этого 0.05 г сорбента помещали в эппендорф, микрошприцом добавляли $1 \mathrm{~cm}^{3}$ растворителя и центрифугировали 5 мин.

\section{Обсуждение результатов}

Исследование физико-химических свойств сорбентов. Удельные площади поверхности для всех МИП на 10-40\% выше, чем НИП (табл. 1). Сорбенты, синтезированные в присутствии темплатов 4-НФ и БФА и в их отсутствии, различаются по удельным площадям поверхности почти в 2 раза. По результатам просвечивающей электронной микроскопии размер наночастиц $\mathrm{Fe}_{3} \mathrm{O}_{4}$ coставил 10-20 нм (рис. 3a). Размер полученных частиц МИП и НИП 60-150 нм (рис. 3б), средний размер около 100 нм.
Намагниченность насыщения непокрытых частиц $\mathrm{Fe}_{3} \mathrm{O}_{4}-60 \mathrm{emu} / \mathrm{g}$, для покрытых полимерами - 51-53 emu/g [20] (рис. 3в). Спектр XRD наночастиц $\mathrm{Fe}_{3} \mathrm{O}_{4}$ содержит характеристические пики $\left(2 \theta=30.38^{\circ}, 35.58^{\circ}, 44.14^{\circ}, 53.48^{\circ}, 57.08^{\circ}\right.$ и $\left.62.66^{\circ}\right)$, соответствующие значениям относительных интенсивностей (211), (311), (400), (422), (511) и (440) (рис. 3 г) [23]. XRD-спектр наночастиц $\mathrm{Fe}_{3} \mathrm{O}_{4}$ показывает, что свойства магнетита сохраняются после покрытия МИП.

Влияние $\mathrm{pH}$ раствора. Установлено, что наиболее эффективно сорбция протекает при рН 3 (рис. 4). При рН 4-5 эффективность сорбции начинает несколько снижаться. Наименее эта зависимость выражена для 2-ХФ, 4-ХФ и алкилфенолов. При рН 8 происходит резкое снижение степеней извлечения, обусловленное, в первую очередь, ионизацией ОНгрупп фенолов и резким повышением их растворимости в щелочной среде. Уменьшение $\mathrm{pH}$ до 2 и ниже приводит также к снижению сорбционных характеристик, особенно МИП. Известно [22], что в щелочной среде НВП гидролизуется с образованием N-винил- $\gamma$-аминомасляной кислоты. Образуются-СООН и NH-группы, которые потенциально способны к образованию водородных связей. Наиболее вероятно, что при синтезе 


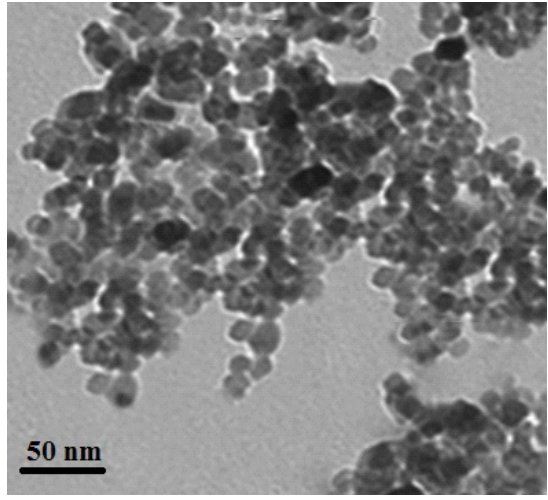

a

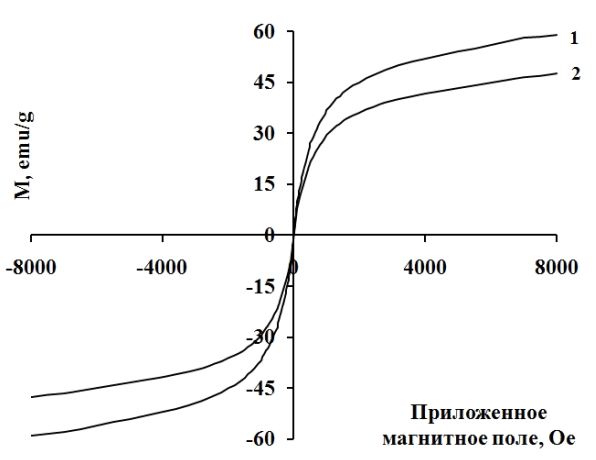

B

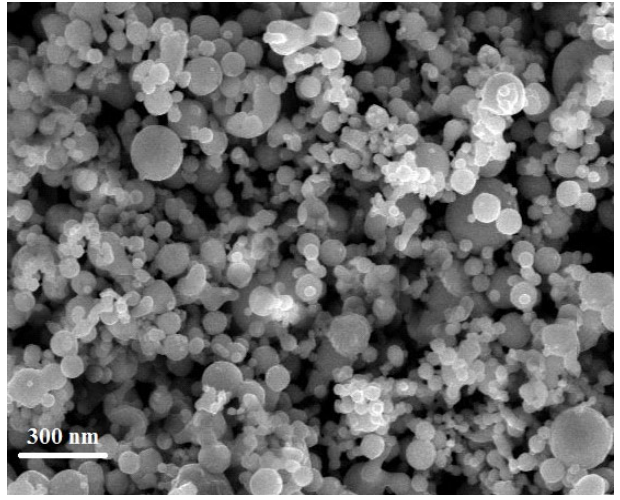

б

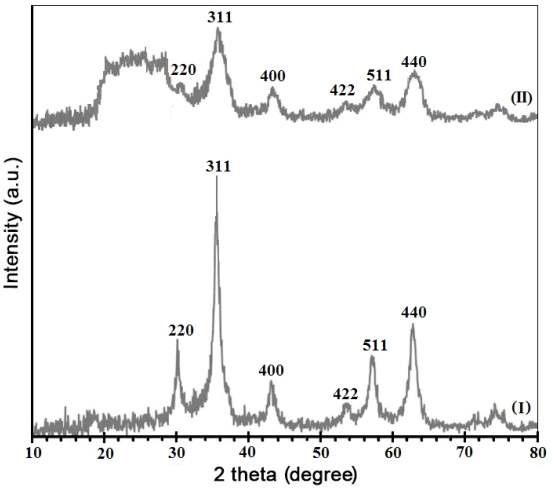

$\Gamma$

Рис. 3. Микрофотографии наночастиц $\mathrm{Fe}_{3} \mathrm{O}_{4}$, полученные с применением просвечивающей электронной микроскопии (а); микрофотография сорбента (на примере МИП-БФА), полученная с применением сканирующей электронной микроскопии (б); кривые намагниченности наночастиц $\mathrm{Fe}_{3} \mathrm{O}_{4}$ (1) и МИП-БФА (2) (в) и XRD-спектр наночастиц $\mathrm{Fe}_{3} \mathrm{O}_{4}(\mathrm{I})$ и МИП-БФА (ІІ) (г).

Fig. 3. Micrographs of $\mathrm{Fe}_{3} \mathrm{O}_{4}$ nanoparticles, obtained using transmission electron microscopy (a); micrograph of the sorbent (for example, MIP-BPA), obtained using scanning electro microscopy (b); magnetization curves of $\mathrm{Fe}_{3} \mathrm{O}_{4}$ (1) nanoparticles and MIP-BPA (2) (c) and XRD spectrum

МИП-4НФ или МИП-БФА возможно образование нескольких водородных связей. Такой комплекс более устойчив, а образующийся после вымывания темплата шаблон значительно менее доступен другим соединениям. В случае 2-НФ и 4-НФ образование Н-связей при синтезе МИП, вероятно, происходит не только c $\mathrm{O}=\mathrm{C}-$ группами пирролидонового кольца, но и за счет $\mathrm{HN}-$ и HOOC-групп и $\mathrm{N}$-винил- $\gamma$-аминомасляной кислоты, некоторые количества которых изначально содержатся в полимере, поскольку синтез осуществляется в слабощелочной среде. Наличие фрагментов Nвинил- $\gamma$-аминомасляной кислоты в исходном сорбенте МИП-4НФ подтверждается ИК-спектрами в диапазоне от
1400 до $1800 \mathrm{~cm}^{-1}$, полученными в процессе синтеза сорбента (рН 7.2, рис. 5a), и после его набухания при рН 10.0 (рис. 5б). При увеличении $\mathrm{pH}$ резко усиливаются колебания при $1408 \mathrm{~cm}^{-1}$ и в обла-

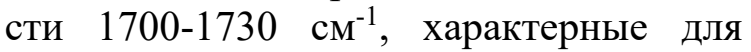
НООС-групп [24] и существенно ослабевает полоса поглощения $1652 \mathrm{~cm}^{-1}$, характерная для колебания карбонильной группы в пирролидоновом кольце. Как следует из спектра МИП-4НФ, полосы, характерные для НООС-группы (колебания при $1408 \mathrm{~cm}^{-1}$ и группа характеристических пиков в области 1700-1725 cм ${ }^{-1}$ ) есть и в спектре исходного полимера при $\mathrm{pH}$ 7.2-7.4, что определяется наличием фрагментов $\mathrm{N}$-винил- $\gamma$-амино-масляной кислоты уже в исходном полимере. 


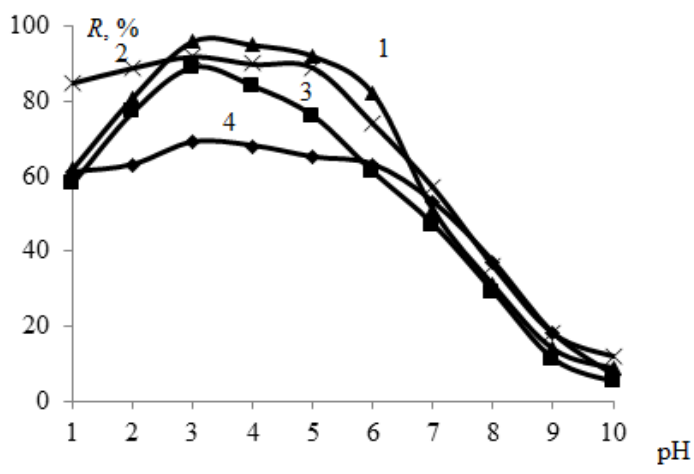

Рис. 4. Зависимость степени извлечения БФА (1), НЛФ (2), 4-НФ (3), 2-ХФ (4) от рН раствора при сорбции МИП: МИП-БФА (1); МИП-НЛФ (2); МИП-4НФ (3); МИП-2ХФ (4).

Fig 4. Dependence of the degree of recovery of BPA (1), NLP (2), 4-NP (3), 2-CP (4) on the $\mathrm{pH}$ of the solution during the sorption of MIP: MIP-BPA (1); MIP-NLP (2); MIP-4NP (3); MIP-2CP (4).

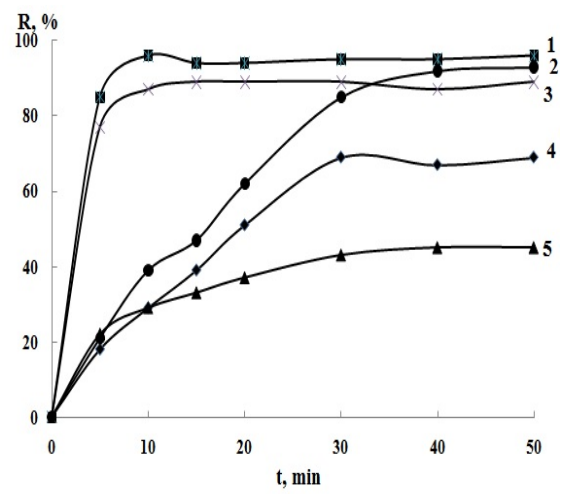

a

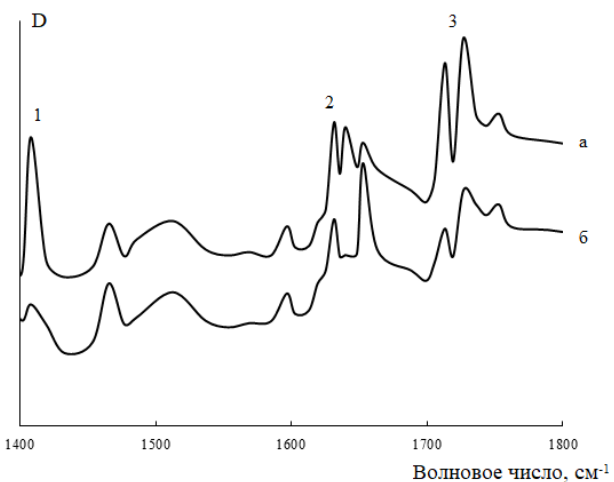

Рис. 5. ИК-Фурье-спектры полимера МИП-4НФ при рН 7.2 (а) и 10 (б); пики (см $\left.{ }^{-1}\right): 1408$ (1), 1652 (2), 1700-1725 (3).

Fig. 5. FT-IR spectra of MIP-4NP polymer at $\mathrm{pH} 7.2$ (a) and $10(\mathrm{~b})$; peaks $\left(\mathrm{cm}^{-1}\right)$ : 1408 (1), 1652 (2), 1700-1725 (3).

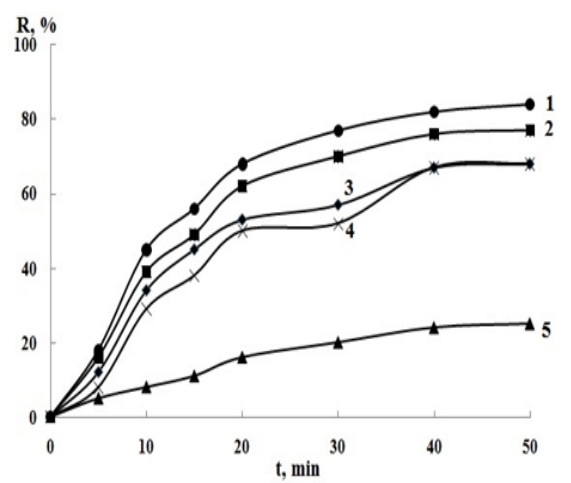

6

Рис. 6. Кинетические кривые сорбции БФА (1), ПТБФ (2), 4-НФ (3), 2-ХФ (4), 2-НФ (5) молекулярно импринтированными (а) и неимпринтированными (б) полимерами.

Fig. 6. Kinetic curves of sorption of BPA (1), PTBP (2), 4-NP (3), 2-CP (4), 2-NP (5) by molecularly imprinted (a) and unimprinted (b) polymers.

Влияние времени контакта фаз. Время достижения сорбционного равновесия существенно меньше для МИП. Максимальное извлечение 4-НФ на МИП-4НФ и БФА на МИП-БФА достигается за 10 мин, 2-ХФ и 4-НФ - 30 мин (рис. 6а), на всех НИП время достижения сорбционного равновесия составляет 30 мин и более (рис. 6б).

Влияние массы сорбента. При увеличении массы сорбента от 0.01 до 0.05 г существенно возрастают степени извлечения веществ (рис. 7а). Количественные показатели сорбции при массах 0.06 и
0.07 г практически не отличаются от результатов, полученных при массе сорбента 0.05 г.

Влияние объема раствора. Отношение массы сорбента к объему раствора важно при массообмене. Чем больше это соотношение, тем меньше эффективность этого процесса. При одинаковой массе сорбента, степень извлечения мало изменяется при увеличении объема раствора до $10 \mathrm{~cm}^{3}$. При больших соотношениях массы сорбента и объема раствора степень извлечения снижается (рис. 7б). 


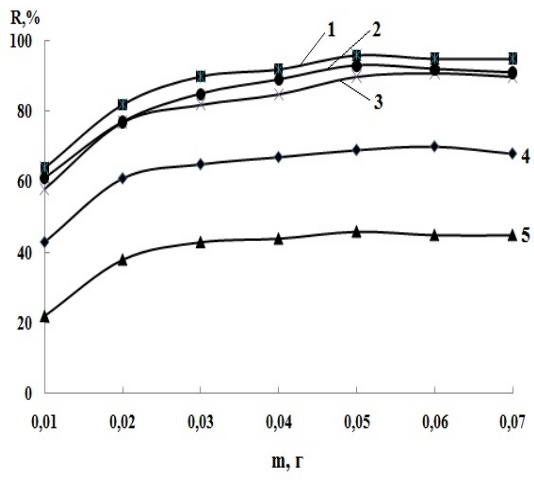

a

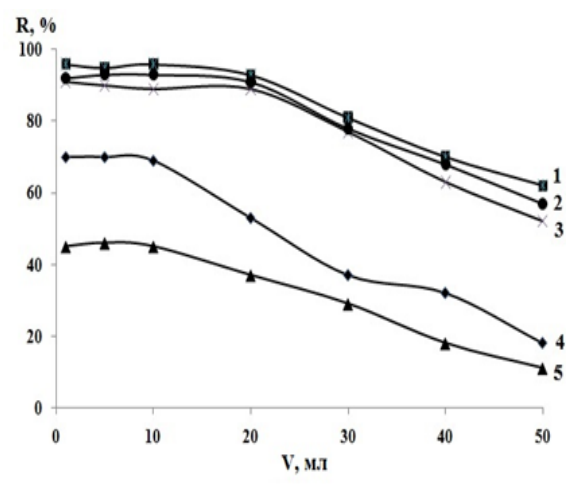

6

Рис. 7. Зависимость степени извлечения ПТБФ (1), БФА (2), 4-НФ (3), 2-ХФ (4), 2-НФ (5) от массы сорбента (а) и объема раствора (б). Сорбенты: 1 - МИП-ПТБФ, 2 - МИП-БФА, 3 - МИП-4НФ, 4 - МИП-2ХФ, 5- МИП-2НФ.

Fig. 7. Dependence of the degree of extraction of PTBP (1), BPA (2), 4-NP (3), 2-CP(4), 2-NP (5) on the mass of the sorbent (a) and the volume of the solution (b). Sorbents:

$$
1 \text { - MIP-PTBP, } 2 \text { - MIP-BPA, } 3 \text { - MIP-4NP, } 4 \text { - MIP-2CP, } 5 \text { - MIP-2NP. }
$$

Таблица 2. Десорбция фенолов с молекулярно импринтированных полимеров различными растворителями (масса сорбента -0.05 г).

Table 2. Desorption of phenols from molecular imprinted polymers by various solvents (sorbent weight- $0.05 \mathrm{~g}$ ).

\begin{tabular}{|c|c|c|c|}
\hline \multirow[t]{2}{*}{ Вещество } & \multicolumn{3}{|c|}{ Степень десорбции, \% } \\
\hline & $\mathrm{NaOH}(\mathrm{pH} 10)$ & $\mathrm{ACN}^{*}$ & $\mathrm{ACT}_{* *}$ \\
\hline $2-X \Phi$ & 99 & $\sim 100$ & 95 \\
\hline $4-X \Phi$ & 98 & 98 & 96 \\
\hline 2-НФ & 95 & 98 & 95 \\
\hline 4-HФ & 95 & 98 & 96 \\
\hline БФА & 97 & 97 & 94 \\
\hline ПТБФ & 98 & 98 & 96 \\
\hline НЛФ & 96 & 97 & 95 \\
\hline ТНЛФ & 96 & 97 & 95 \\
\hline 4-ОФ & 97 & 98 & 95 \\
\hline
\end{tabular}

Десорбция фенолов. Степень десорбции фенолов с применением органических растворителей и щелочных растворов достаточно высока и составляет 9498\% (табл. 2) и практически не зависит от природы десорбента.

\section{Заключение}

На основе $\mathrm{N}$-винилпирролидона и этиленгликольдиметакрилата синтезированы 9 МИП с отпечатками 2-ХФ, 4-ХФ, 2-НФ, 4-НФ, БФА, ПТБФ, НЛФ, ТНЛФ и 4-ОФ и полимера без молекулярных отпечатков. Размер частиц полученных магнитных полимеров составляет около
100 нм, намагниченность насыщения 51$53 \mathrm{emu} / \mathrm{g}$. Наибольшие значения $I F$ для МИП-4НФ $\quad(I F=3.8) \quad$ и МИП-БФА $(I F=7.1)$, наименьшие - для полимеров с отпечатками хлорфенолов $(I F=1.1)$. Эффективность сорбции при применении МИП существенно возрастает. Наибольшие значения коэффициентов селективности достигаются при сорбции на МИП-4НФ и МИП-БФА, для большинства фенолов $2-2.5$, для 4-НФ - 3.8, для БФА - 7.1. Степени извлечения фенолов МИП составляют 69-96\%, для 2НФ не более $45 \%$. 


\section{Список литературы}

1. Zheng J., Chen B., Thanyamanta W., Hawboldt K. et al. // Mar. Pollut. Bull. 2016. Vol. 104. pp. 7-19. doi: 10.1016/ j.marpolbul.2016.01.004

2. Bakke T., Klungsøyr J., Sanni S. // Mar. Environ. Res. 2013.Vol. 92. pp. 154-169. doi: 10.1016/j. marenvres.2013.09.012.

3. ГН 2.1.5.1315-03. Предельно допустимые концентрации (ПДК) химических веществ в воде водных объектов хозяйственно-питьевого и культурно-бытового водопользования.

4. Приказ Минсельхоза России от 13.12.2016 N 552 (ред. от 12.10.2018) «Об утверждении нормативов качества воды водных объектов рыбохозяйственного значения, в том числе нормативов предельно допустимых концентраций вредных веществ в водах водных объектов рыбохозяйственного значения».

5. СанПиН 2.1.4.1074-01 Питьевая вода. Гигиенические требования к качеству воды централизованных систем питьевого водоснабжения. Контроль качества. Гигиенические требования к обеспечению безопасности систем горячего водоснабжения. http://docs.cntd.ru/document/901798042

6. Rodríguez I., Llompart M.P., Cela R. // J. Chromatogr. A. 2000. Vol. 885. pp. 291-304. doi: 10.1016/S0021-9673(00) 00116-3.

7. Bagheri H., Mohammadi A., Salemi A. // Anal. Chim. Acta. 2004. Vol. 513. pp. 445-449. doi: 10.1016/j.aca.2004.03.020.

8. Prieto A., Araujo L., Navalon A., Vilchez J. // Curr. Anal. Chem. 2010. Vol. 5. pp. 219-224. doi: 10.2174/157341109788680309.

9. Turiel E., Martín-Esteban A. // TrAC Trends Anal. Chem. 2019. Vol. 118. pp. 574586. doi: 10.1016/j.trac.2019.06.016.

10. Surikumaran H., Mohamad S., Muhamad Sarih N., Muggundha Raoov. // Separ. Sci. Technol. 2015. Vol. 6395. pp. 2342-235. doi: 10.1080/01496395.2015.1043016.

11. El-Sheikh A.H., Al-Quse R.W., ElBarghouthi M.I., Al-Masri F.S. // Talanta.
2010. Vol. 83. pp. 667-673. doi: $10.1016 /$ j. talanta.2010.10.022.

12. Caro E., Marc'e R.M., Cormack P.G., Sherrington D.C. et al. // J. Chromatogr. A. 2003. Vol. 995. pp. 233-238. doi: 10.1016/S0021-9673(03)00543-0.

13. Feng Q.-Z., Zhao L.-X., Yan W., Lin J.M. et al. // J. Hazard Mater. 2009. Vol. 167. pp 282-288. doi: 10.1016/j.jhazmat.2008.12.115.

14. Gryshchenko A.O., Bottaro C.S. // Int. J. Mol. Sci. 2014. Vol. 15. pp. 1338-1357. doi: 10.3390/ijms15011338.

15. Zhao Q., Lu Q., Feng Y.Q. //Anal. Bioanal. Chem. 2013. Vol. 405. pp. 4765-4776. doi: 10.1007/s00216-013-6866-5.

16. Xu Z., Ding L., Long Y.J., Xu L.G. et al. // Anal. Methods. 2011. Vol. 3. pp. 1737-1744. doi: 10.1039/C1AY05206C.

17. Wu X.Q., Wang X.Y., Lu W.H., Wang X.R. et al. // J. Chromatogr. A. 2016. Vol. 1435. pp. 30-38. doi: 10.1016/j.chroma.2016. 01.040 .

18. Li F., Cai C.C., Cheng J., Zhou H.B. et al. // Microchim. Acta. 2015. Vol. 182. pp. 25032511. doi: 10.1007/s00604-015-1619-0.

19. Xiao D.L., Lu T., Zeng R., Bi Y.P. // Microchim. Acta. 2016. Vol. 183. pp. 2655-2675. doi: 10.1007/s00604-016-1928-y.

20. Губин А.С., Суханов П.Т., Кушнир А.А., Проскурякова Е.Д. // Журнал прикладной химии. 2018. Т. 91. № 10. С. 1431-1440.

21. Губин А.С., Суханов П.Т., Санникова Н.Ю., Проскурякова Е.Д. и др. // Журнал аналитической химии. 2019. Т.74. № 7S. С. S16-S23.

22. Чурилина Е.В., Суханов П.Т., Ермак С.С., Коренман Я.И. и др. // Журнал аналитической химии. 2012. Т. 67. № 9. С. 855859.

23. Silva V.A.J., Andrade P.L., Silva M.P.C., Bustamante D.A. et al. // Journal of Magnetism and Magnetic Materials. 2013. Vol. 343. pp. 138-143. doi: 10.1016/j.jmmm.2013.04.062.

24. Ji Y., Yin J., Xu Z., Zhao C. et al. // Anal. Bioanal. Chem. 2009. Vol. 395. pp. 1125-1133. doi: 10.1007/s00216-009-3020-5. 


\title{
Sorption concentration of phenols from aqueous media by magnetic molecular imprinted polymers based on $\mathrm{N}$-vinylpyrrolidone
}

\author{
(C) 2021 Gubin A.S., Kushnir A.A., Sukhanov P.T. \\ Voronezh State University of Engineering Technologies, Voronezh
}

\begin{abstract}
Phenols are one of the most extensive groups of priority organic pollutants with mutagenic and carcinogenic properties. They are characterized by very low maximum permissible concentrations, which are difficult to determine by many modern physicochemical methods without preliminary concentration. The solution to this problem is achieved by modern approaches to solid-phase concentration, in particular, by using molecularly imprinted polymer sorbents with magnetic properties. The possibility of obtaining a magnetic sorbent based on a molecularly imprinted polymer has been studied, where N-vinylpyrrolidone was used as a functional monomer, ethylene glycol dimethacrylate was used as a crosslinking agent, and phenols were used as templates.

Nine MIPs were synthesized with imprints of 2-chlorophenol, 4-chlorophenol, 2-nitrophenol, 4nitrophenol, bisphenol A, $n$-tert-butylphenol, nonylphenol, tert-nonylphenol and 4-octylphenol and polymer without molecular imprints. The particle size of the obtained polymers was about $100 \mathrm{~nm}$, the saturation magnetization was $51-53 \mathrm{emu} / \mathrm{g}$. The highest imprinting factors $(I F)$ were achieved for MIPs with imprints of 4-nitrophenol $(I F=3.8)$ and bisphenol A $(I F=7.1)$, the lowest imprinting factors were obtained for polymers with chlorophenol imprints $(I F=1.1)$. It was found that phenols were most efficiently sorbed at $\mathrm{pH} 3$. The highest values of the selectivity coefficients were achieved upon sorption on MIP-4NP and MIP-BPA. The effectiveness of the extraction of MIP phenols ranged from 69 to $96 \%$, for 2-NP it was not higher than $45 \%$; on an unimprinted polymer, the effectiveness of extraction for most phenols was significantly lower.
\end{abstract}

Keywords: sorption, phenols, chlorophenols, nitrophenols, molecularly imprinted polymer.

\section{References}

1. Zheng J., Chen B., Thanyamanta W., Hawboldt K. et al., Mar. Pollut. Bull, 2016, Vol. 104, pp. 7-19. doi: 10.1016/ j.marpolbul. 2016.01.004

2. Bakke T., Klungsøyr J., Sanni S., Mar. Environ. Res, 2013, Vol. 92, pp. 154-169. doi: 10.1016/j. marenvres.2013.09.012.

3. GN 2.1.5.1315-03 (Hygienic Regulations) (2020) Maximum permissible concentrations of chemical substances in waters for general and drinking purposes (in Russian).

4. Order (2016) The Order of Ministry of Agriculture of the Russian Federation (No 552, 13.12.2016) "Approval of water quality standards for water bodies of fishery value including the standards of maximum permissible concentrations of harmful substances in the waters of water bodies of fishery value (as amended on October 12, 2018)" (in Russian).

5. SanPiN 2.1.4.1074-01 (Sanitary Rules and Regulations) (2020) Drinking water. Hygienic requirements for water quality. Quality control. Hygienic requirements for hot water systems safety (in Russian).
6. Rodríguez I., Llompart M.P., Cela R., J. Chromatogr. A, 2000, Vol. 885, pp. 291-304. doi: 10.1016/S0021-9673(00) 00116-3.

7. Bagheri H., Mohammadi A., Salemi A., Anal. Chim. Acta, 2004, Vol. 513, pp. 445-449. doi: 10.1016/j.aca.2004.03.020.

8. Prieto A., Araujo L., Navalon A., Vilchez J., Curr. Anal. Chem, 2010, Vol. 5, pp. 219224. doi: 10.2174/157341109788680309.

9. Turiel E., Martín-Esteban A., $\operatorname{Tr} A C$ Trends Anal. Chem, 2019, Vol. 118, pp. 574-586. doi: 10.1016/j.trac.2019.06.016.

10. Surikumaran H., Mohamad S., Muhamad Sarih N., Muggundha Raoov., Separ. Sci. Technol, 2015, Vol. 6395, pp. 2342-235. doi: 10.1080/01496395.2015.1043016.

11. El-Sheikh A.H., Al-Quse R.W., ElBarghouthi M.I., Al-Masri F.S., Talanta, 2010. Vol. 83, pp. 667-673. doi: 10.1016/j. talanta.2010.10.022.

12. Caro E., Marc'e R.M., Cormack P.G., Sherrington D.C. et al., J. Chromatogr. A, 2003, Vol. 995, pp. 233-238. doi: 10.1016/S00219673(03)00543-0. 
13. Feng Q.-Z., Zhao L.-X., Yan W., Lin J.M. et al., J. Hazard. Mater., 2009. Vol. 167, pp 282-288. doi: 10.1016/j.jhazmat.2008.12.115.

14. Gryshchenko A.O., Bottaro C.S., Int. J. Mol. Sci., 2014, Vol. 15, pp. 1338-1357. doi: 10.3390/ijms15011338.

15. Zhao Q., Lu Q., Feng Y.Q., Anal. Bioanal. Chem., 2013, Vol. 405, pp. 4765-4776. doi: 10.1007/s00216-013-6866-5.

16. Xu Z., Ding L., Long Y.J., Xu L.G. et al., Anal. Methods, 2011, Vol. 3, pp. 1737-1744. doi: 10.1039/C1AY05206C.

17. Wu X.Q., Wang X.Y., Lu W.H., Wang X.R. et al., J. Chromatogr. A, 2016, Vol. 1435, pp.30-38. doi: 10.1016/j.chroma.2016.01.040.

18. Li F., Cai C.C., Cheng J., Zhou H.B. et al., Microchim. Acta, 2015, Vol. 182, pp. 25032511. doi: 10.1007/s00604-015-1619-0.

19. Xiao D.L., Lu T., Zeng R., Bi Y.P., Microchim. Acta, 2016, Vol. 183, pp. 2655-2675. doi: 10.1007/s00604-016-1928-y.

Губин Александр Сергеевич - к.Х.н., доцент кафедры технологии органических соединений, переработки полимеров и техносферной безопасности, Воронежский государственный университет инженерных технологий, Воронеж.

Кушнир Алексей Алексеевич - к.Х.н., доцент кафедры технологии органических соединений, переработки полимеров и техносферной безопасности, Воронежский государственный университет инженерных технологий, Воронеж.

Суханов Павел Тихонович - Д.х.н., профессор кафедры физической и аналитической химии, Воронежский государственный университет инженерных технологий, Воронеж
20. Gubin A.S., Sukhanov P.T., Kushnir A.A., Proskuryakova E.D., Russ. J. Appl. Chem., 2018, Vol. 91, pp. 1626-1634. doi: 10.1134 S1070427218100099.

21. Gubin A.S., Sukhanov P.T., Sannikova N.Y., Proskuryakova E.D. et al., J. Anal. Chem., 2019, Vol. 74, Suppl. 1, pp. S11-S17. doi:10.1134/s1061934819070116.

22. Churilina E.V., Sukhanov P.T., Ermak S.S., Korenman Ya.I. et al., J. Analyt. Chem., 2012, Vol. 67, No 9, pp 767-771. doi: $10.1134 / \mathrm{S} 1061934812050048$.

23.Silva V.A.J., Andrade P.L., Silva M.P.C., Bustamante D.A., et al., Journal of Magnetism and Magnetic Materials, 2013, Vol. 343. pp. 138-143. doi: 10.1016/j.jmmm.2013.04.062.

24. Ji Y., Yin J., Xu Z., Zhao C. et al., Anal. Bioanal. Chem., 2009, Vol. 395, pp. 11251133. doi: 10.1007/s00216-009-3020-5.

Gubin Aleksander S. - Ph.D., Associate Professor, Department of Compound Technology, Polymer Converters and Technosphere Safety, Voronezh state university of engineering technologies, Voronezh, email: goubinne@mail.ru

Kushnir Aleksei A. - Ph.D., Associate Professor, Department of Compound Technology, Polymer Converters and Technosphere Safety, Voronezh state university of engineering technologies, Voronezh. email: kushnir_aleksei@mail.ru

Sukhanov Pavel T. - professor, doctor of science (chemistry), Department of Physical and Analytical Chemistry, Voronezh state university of engineering technologies, Voronezh. e-mail: pavel.suhanov@mail.ru 